\title{
No pharmacokinetic interactions between candesartan and amlodipine following multiple oral administrations in healthy subjects
}

This article was published in the following Dove Press journal:

Drug Design, Development and Therapy

\author{
Jung-Ryul Kim ${ }^{1,2}$ \\ Seokuee Kim' \\ Wooseong Huh ${ }^{1,3}$ \\ Jae-Wook Ko' \\ 'Department of Clinical Pharmacology \\ and Therapeutics, Samsung \\ Medical Center, Republic of Korea; \\ ${ }^{2}$ Department of Clinical Research \\ Design \& Evaluation, SAIHST, \\ Sungkyunkwan University, Republic \\ of Korea; ${ }^{3}$ Department of Internal \\ Medicine, Samsung Medical Center, \\ Sungkyunkwan University School of \\ Medicine, Seoul, Republic of Korea
}

Correspondence: Jae-Wook Ko Department of Clinical Pharmacology and Therapeutics, Samsung Medical Center, 9th Floor, Main Building, 8I Irwon-ro, Gangnam-gu, Seoul 0635I, Republic of Korea

$\mathrm{Tel}+82234103690$

Fax +82234100915

Email jw070I.ko@samsung.com
Purpose: To evaluate the pharmacokinetics and pharmacodynamics of candesartan and amlodipine in the absence and presence of each other in healthy subjects.

Methods: This study consisted of two parts: part 1, the effect of amlodipine on candesartan; part 2, the effect of candesartan on amlodipine. Each part was designed as a randomized, open-label, two-sequence, two-period, two-intervention crossover study with 20 subjects and performed separately in different populations. Pharmacokinetic assessments were performed over 48 hours for candesartan in part 1 and 72 hours for amlodipine in part 2 after drug administration on Day 10. Safety data included the results of physical examinations, clinical laboratory tests, vital signs, an electrocardiogram, and adverse events.

Results: For both candesartan and amlodipine, the $90 \%$ confidence intervals for the geometric mean ratios of area under the concentration-time curve from time zero to the time of dosing interval of 24 hours and maximum concentration after drug administration fell within the bioequivalence acceptance criteria. Although this study was conducted in normotensive subjects, blood pressure lowering effects were observed in all intervention groups and co-administration of candesartan and amlodipine reduced blood pressure more than amlodipine alone, but similar to candesartan alone. No serious adverse event was reported throughout the study, and all treatment emergent adverse events were mild to moderate in severity and were recovered without sequelae.

Conclusion: Co-administration of candesartan and amlodipine did not change the systemic exposure of each drug alone in healthy subjects. The administration of candesartan $32 \mathrm{mg}$ alone, amlodipine $10 \mathrm{mg}$ alone, and co-administration of candesartan and amlodipine were well tolerated during the study.

Keywords: interaction, candesartan, amlodipine, combination

\section{Introduction}

Hypertension is one of the most important risk factors of cardiovascular disease. For the management of hypertension, it is required to reduce blood pressure (BP) to target levels by using antihypertensive drugs. The antihypertensive drugs are divided into several classes such as thiazide-type diuretic, calcium channel blocker, angiotensinconverting enzyme inhibitor, and angiotensin receptor blocker according to their action mechanisms. ${ }^{1}$ Monotherapy with one class drug is usually not adequate for patients with high-risk conditions, and most hypertensive patients will require two or more drugs with different action mechanisms to achieve goal BP. ${ }^{2}$

Candesartan is one of the angiotensin receptor blockers (ARBs) and amlodipine is the most widely used calcium channel blocker for the treatment of hypertension. 
Since the action mechanisms of candesartan and amlodipine are quite different, combination therapy with these two drugs was effective for hypertensive patients. ${ }^{3-5}$ Moreover, candesartan has shown more favorable tolerability in terms of developing peripheral edema compared to amlodipine. ${ }^{6}$ For patients whose BP is uncontrolled by low dose amlodipine alone, it can be better to use candesartan in combination with amlodipine than to increase the dose of amlodipine. To facilitate this rational prescribing, fixed-dose combinations of candesartan and amlodipine have been available in Japan and Republic of Korea., ${ }^{7,8}$

A large number of drug interactions are attributable to the inhibition or induction of CYP/CYP450 (CYP) enzymes. ${ }^{9}$ Since amlodipine is extensively metabolized by the CYP3A4, its systemic exposure may be affected by CYP inhibitors and inducers. ${ }^{10}$ In contrast, candesartan is mainly excreted unchanged in urine and feces. ${ }^{11}$ Although they have different disposition and elimination pathways, it is recommended to address the drug interaction potential if they are commonly used in combination. ${ }^{12,13}$ The clinical efficacy of combination therapy with candesartan and amlodipine in hypertensive patients is well demonstrated; however, there is a lack of study explicitly reporting drug interactions between these drugs. The purpose of this study was to evaluate the pharmacokinetics and pharmacodynamics of candesartan and amlodipine in the absence and presence of each other in healthy subjects.

\section{Materials and methods Study design and subjects}

This study consisted of two parts: part 1, the effect of amlodipine on candesartan; part 2, the effect of candesartan on amlodipine. Each part was designed as a randomized, open-label, two-sequence, two-period, two-intervention (administration of one drug with the absence or presence of the other drug) crossover study with 20 subjects and performed separately in different populations. In each part, subjects were randomized to receive either one drug with absence followed by presence of the other drug, or vice versa.
Each intervention was separated by a 14-day washout period except when subjects received candesartan alone first and then candesartan with amlodipine after a washout period of 4 days in part 1 (Table 1 ).

Eligible subjects were males between 20-55 years old with body mass index of 18.5-27.0 and were healthy as determined by medical history, physical examination, vital signs, 12-lead electrocardiogram (ECG), and clinical laboratory tests (hematology, blood chemistry, urinalysis, serology) within 28 days prior to enrolment in the study. Subjects were excluded if they had donated blood in the 2 months previous to the study or participated in any clinical trials in the month previous to the study or had received any drug that affects the pharmacokinetics of candesartan or amlodipine in the month previous to the study. During the study, subjects were required to abstain from strenuous physical exercise, smoking, and products, such as over-the-counter medications or beverages containing alcohol or caffeine.

The intra-subject coefficients of variation of the PK exposure of candesartan and amlodipine were assumed to be $18 \%$ and $10 \%$, respectively, based on the results of a previous clinical study. ${ }^{21,22}$ With a sample size of 16 , a difference of $20 \%$ in the log-transformed PK parameters of candesartan and amlodipine could be detected with $>90 \%$ test power at a significance level of 0.05 . Assuming a drop-out, the total number of subjects for each part was 20 (10 subjects per sequence).

The protocol of this study was approved by the Samsung Medical Center Institutional Review Board and the Ministry of Food and Drug Safety in Republic of Korea before the initiation of the study. The study was conducted in accordance with the Declaration of Helsinki, Korean Good Clinical Practice. All subjects gave written informed consent prior to any study procedures.

\section{Dosing and sampling schedules}

Subjects received candesartan alone, amlodipine alone, or both candesartan and amlodipine for 10 days in each part. Candesartan 32 mg $\left(\right.$ Atacand $^{\circledR}$, AstraZeneca Korea, Seoul, Korea)

Table I Study design and drug administration scheme

\begin{tabular}{|c|c|c|c|c|}
\hline Part & Sequence & Intervention & Washout & Intervention \\
\hline \multirow[t]{2}{*}{1} & 1 & Candesartan $^{\mathrm{a}}$ & 14 days & Candesartan + amlodipine ${ }^{b}$ \\
\hline & 2 & Candesartan + amlodipine ${ }^{\mathrm{b}}$ & 14 days & Candesartan ${ }^{\mathrm{a}}$ \\
\hline \multirow[t]{2}{*}{2} & I & Amlodipine $^{c}$ & 14 days & Amlodipine + candesartan \\
\hline & 2 & Amlodipine + candesartan ${ }^{\mathrm{b}}$ & 14 days & Amlodipine $^{c}$ \\
\hline
\end{tabular}

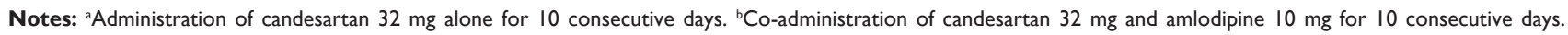
'Administration of amlodipine $10 \mathrm{mg}$ alone for 10 consecutive days. 
and amlodipine $10 \mathrm{mg}$ (Norvasc ${ }^{\circledR}$, Pfizer Korea, Seoul, Korea) were administered with $240 \mathrm{~mL}$ water regardless of meals, while the same were administered under fasted conditions on Day 10. Subjects visited the Samsung Medical Center for drug administration on Days 1, 4, 7, 8, and 9 and documented timing and administration of drugs with dosing diaries on Days 2, 3, 5 and 6. Pharmacokinetic assessments were performed over 48 hours for candesartan in part 1 and 72 hours for amlodipine in part 2 after drug administration on Day 10. For the pharmacokinetic analysis of candesartan, blood samples $(8 \mathrm{~mL})$ were collected at predose and at 1, 2, 3, 4, 5, $6,8,12,24$, and 48 hours postdose on day 10 in part 1 . As for amlodipine, blood samples were collected at predose and at 1 , $2,3,4,5,6,8,12,24,48$, and 72 hours postdose on Day 10 in part 2. Blood samples were centrifuged at 1,800 $\mathrm{g}$ for 10 minutes and plasma was collected and frozen at $-70^{\circ} \mathrm{C}$ until analysis.

\section{Determination of plasma concentrations}

Plasma samples for PK analysis were determined using ultra performance liquid chromatography - tandem mass spectrometry (UPLC-MS/MS) with a validated methodology to determine plasma concentrations of candesartan and amlodipine.

In the candesartan assay, chromatography (Waters Acquity UPLC ${ }^{\text {TM }}$ System; Waters Corporation, Milford, MA, USA) was performed with a Waters Acquity $\mathrm{UPLC}^{\circledR} \mathrm{BEH}$ C18 column $(1.7 \mu \mathrm{m}, 2.1 \times 50 \mathrm{~mm}$; Waters $)$ while the column temperature was maintained at $30^{\circ} \mathrm{C} \pm 5^{\circ} \mathrm{C}$. The standards for candesartan and the internal standard (IS), candesartan_d5, were provided by Toronto Research Chemicals Inc. (North York, ON, Canada). The mobile phase for candesartan consisted of a mixture of (A) $0.1 \%$ (vol/vol) formic acid in distilled water and (B) $0.1 \%$ ( $\mathrm{vol} / \mathrm{vol}$ ) formic acid in acetonitrile $(\mathrm{A}: \mathrm{B}=6: 4, \mathrm{vol} / \mathrm{vol})$ with a flow rate of $0.4 \mathrm{~mL} / \mathrm{min}$. Detection of candesartan was conducted by a Waters Micromass Quattro Premier ${ }^{\mathrm{TM}}$ XE Mass Spectrometer (Waters Corporation) with a positive electrospray ionization multiple reaction monitoring mode set to transmit at $\mathrm{m} / \mathrm{z} 440.86 \rightarrow 262.85$ and $445.92 \rightarrow 267.88$ for candesartan and the internal standard, respectively. The assay was linear in the concentration ranges of 5-1,000 $\mu \mathrm{g} / \mathrm{L}$ and the lower limit of quantification was $5.0 \mu \mathrm{g} / \mathrm{L}$ in the candesartan assay. A mixture of $50 \mu \mathrm{L}$ aliquot of plasma sample and $10 \mu \mathrm{L}$ of IS working solution (candesartan-d5 $1.50 \mu \mathrm{g} / \mathrm{mL}$ in 70\% methanol [vol/vol]) was prepared. The prepared mixture was deproteinized by 150 $\mu \mathrm{L}$ volume of pure acetonitrile. Then, each $100 \mu \mathrm{L}$ of the supernatant was diluted with $200 \mu \mathrm{L}$ of $0.1 \%$ formic acid.
The $5 \mu \mathrm{L}$ aliquot was injected into the LC/MS/MS system. The intrabatch and interbatch precision (\%relative SD) for candesartan in plasma samples was less than $9.8 \%$ and $10.4 \%$, respectively. The intrabatch and interbatch accuracy (\%deviation of mean from theoretical) for candesartan in plasma samples ranged between $4.7 \%$ and $7.5 \%$, and $-3.4 \%$ and $7.1 \%$, respectively.

In the amlodipine assay, chromatography (Waters Acquity UPLC ${ }^{\text {TM }}$ System) was performed with a Waters Acquity UPLC ${ }^{\circledR} \mathrm{BEH} \mathrm{C} 18$ column $(1.7 \mu \mathrm{m}, 2.1 \times 50 \mathrm{~mm})$ while the column temperature was maintained at $30^{\circ} \mathrm{C}$ $\pm 5^{\circ} \mathrm{C}$. The standards for amlodipine and the IS, amlodipine_d4 maleic acid salt, were provided by Hana Pharam Co., Ltd (Seoul, Korea) and Toronto Research Chemicals Inc., respectively. The mobile phase consisted of: (A) $0.1 \%$ ( $\mathrm{vol} / \mathrm{vol}$ ) formic acid in distilled water and (B) $0.1 \%$ (vol/ vol) formic acid in acetonitrile, under gradient condition was changed as follows: (A) $70 \%$ at 0.00 and 2.30 minutes; (A) $10 \%$ at 2.40 and 3.00 minutes; and (A) $70 \%$ at 3.10 and 3.50 minutes. Detection of candesartan was conducted by a Waters Xevo ${ }^{\text {TM }}$ TQ-S Mass Spectrometer (Waters Corporation) with a positive electrospray ionization multiple reaction monitoring mode set to transmit at $\mathrm{m} / \mathrm{z} 409.23 \rightarrow 238.15$ and $413.23 \rightarrow 238.15$ for amlodipine and the internal standard, respectively. The assay was linear in the concentration ranges of $0.05-50 \mu \mathrm{g} / \mathrm{L}$ and the lower limit of quantification was $0.05 \mu \mathrm{g} / \mathrm{L}$ in the amlodipine assay. Plasma $(100 \mu \mathrm{L})$ was added to the IS working solution (amlodipine-d4 maleic acid salt, $10 \mu \mathrm{g}$ of $20 \mu \mathrm{g} / \mathrm{mL}$ in $50 \%$ methanol [vol/vol]). The mixture sample was deproteinized by $250 \mu \mathrm{L}$ volume of pure acetonitrile. Each $200 \mu \mathrm{L}$ of the supernatant was diluted with $300 \mu \mathrm{L}$ of $0.1 \%$ formic acid. The $20 \mu \mathrm{L}$ of mixture was injected into the LC/MS/MS system. The intrabatch and interbatch precision for amlodipine in plasma samples was less than $3.0 \%$ and $6.0 \%$, respectively. The intrabatch and interbatch accuracy for amlodipine in plasma samples ranged between $-7.2 \%$ and $-2.0 \%$, and $-2.0 \%$ and $-0.7 \%$, respectively.

\section{Assessments}

Noncompartmental analysis was used for the pharmacokinetics of candesartan and amlodipine. Under steady state conditions, the following pharmacokinetic parameters were determined using Phoenix WinNonlin 6.3 (Certara, St Louis, MO, USA): maximum concentration after drug administration $\left(\mathrm{C}_{\max }\right)$; area under the concentration-time curve from time zero to the time of dosing interval of 24 hours $\left(\mathrm{AUC}_{\tau}\right)$; time to reach $\mathrm{C}_{\max }\left(\mathrm{t}_{\max }\right)$; terminal elimination 
half-life $\left(\mathrm{t}_{1 / 2}\right)$; and the concentration at predose on Day 10 $\left(\mathrm{C}_{\text {trough }}\right)$. For evaluating the pharmacodynamics, systolic blood pressure (SBP), diastolic blood pressure (DBP), and pulse rate $(\mathrm{PR})$ were measured in sitting position at predose and $2,4,6,8,12$, and 24 hours postdose on Day 10 as well as baseline on Day 1. Safety was assessed throughout the study by evaluating treatment-emergent adverse events (TEAEs), clinical laboratory tests, vital signs, physical examinations, and ECG. Particularly, BP decreased by more than expected in healthy subjects following a hypertensive drug administration was documented as a TEAE.

\section{Statistical analysis}

The pharmacokinetic parameters except $t_{\text {max }}$ were logtransformed before analysis. The effect of co-administration of candesartan and amlodipine in comparison with each drug alone was analyzed using a linear mixed effects model. The statistical model included sequence, period and intervention as fixed factors, and subjects nested within sequence as a random factor. For $\mathrm{C}_{\max }$ and $\mathrm{AUC}_{\tau}$, the geometric means ratios (GMR) and their 90\% CI were obtained by backtransformation to the original scale to estimate an interaction effect. Lack of an interaction effect on the pharmacokinetics would be concluded if the $90 \%$ CIs of the GMRs were contained within 0.80 and 1.25 for both $\mathrm{C}_{\max }$ and $\mathrm{AUC}_{\tau}$. The Wilcoxon signed-rank test was used to analyze the difference between interventions for $t_{\text {max }}$. As for SBP, DBP, and PR, maximum change from baseline and trend over time were compared using a linear mixed effects model for repeated measurements with first-order autoregressive covariance structure. Demographic characteristics were summarized using descriptive statistics and all pharmacokinetic parameters were summarized by intervention group. All statistical analyses were performed using SAS Enterprise Guide 7.1 (SAS Institute Inc., Cary, NC, USA).
Based on the known pharmacokinetic profile of candesartan and amlodipine, the sample size of 20 subjects provided $>90 \%$ power to discriminate $20 \%$ differences in exposures by pharmacokinetic equivalence test using a linear mixed effects model appropriate for a two-way crossover.

\section{Results \\ Subjects}

Twenty subjects in each part were enrolled and completed without any drop-out. The demographic characteristics of subjects are summarized in Table 2. Particularly, baseline vital signs were similar between interventions in each part.

\section{Candesartan pharmacokinetics}

Plasma candesartan levels reached a peak at about 5 hours, and then declined with half-lives of about 10 hours (Figure 1A). The pharmacokinetic parameters of candesartan with and without amlodipine are presented in Table 3 . The $90 \%$ CIs of the GMR for $\mathrm{C}_{\max }$ and $\mathrm{AUC}_{\tau}$ were contained within the predefined limits of $0.80-1.25$. There was no statistically significant difference in $\mathrm{t}_{\max }, \mathrm{t}_{1 / 2}$, and $\mathrm{C}_{\text {trough }}$ following co-administration of candesartan and amlodipine compared to candesartan alone (Table 3 ).

\section{Amlodipine pharmacokinetics}

Plasma amlodipine levels reached a peak at 6 hours, and then declined with half-lives of about 50 hours (Figure 1B). The pharmacokinetic parameters of amlodipine by intervention group are presented in Table 3. The 90\% CIs of the GMR for $\mathrm{C}_{\max }$ and $\mathrm{AUC}_{\tau}$ were contained within the predefined limits of $0.80-1.25$. There was no statistically significant difference in $\mathrm{t}_{\max }, \mathrm{t}_{1 / 2}$, and $\mathrm{C}_{\text {trough }}$ following co-administration of candesartan and amlodipine compared to amlodipine alone (Table 3).

Table 2 Demographic and baseline characteristics of subjects

\begin{tabular}{|c|c|c|c|c|}
\hline Variable & $\begin{array}{l}\text { Part I } \\
(n=20)\end{array}$ & & $\begin{array}{l}\text { Part 2 } \\
(\mathrm{n}=20)\end{array}$ & \\
\hline Age (year) & $30 \pm 7$ & & $31 \pm 8$ & \\
\hline Weight (kg) & $73.3 \pm 7.5$ & & $69.6 \pm 8.1$ & \\
\hline Height (cm) & $174.9 \pm 5.3$ & & $175.5 \pm 5.0$ & \\
\hline \multirow[t]{2}{*}{ Body mass index $\left(\mathrm{kg} / \mathrm{m}^{2}\right)$} & $24.0 \pm 2.3$ & & $22.6 \pm 2.4$ & \\
\hline & Amlodipine + candesartan & Candesartan & Candesartan + amlodipine & Amlodipine \\
\hline Systolic blood pressure $(\mathrm{mmHg})$ & $125.0 \pm 8.2$ & $128.7 \pm 9.5$ & $124.4 \pm \mid 2.1$ & $123.9 \pm 12.0$ \\
\hline Diastolic blood pressure $(\mathrm{mmHg})$ & $76.0 \pm 7.3$ & $75.0 \pm 7.0$ & $72.8 \pm 8.8$ & $71.7 \pm 7.8$ \\
\hline Pulse rate (beats/min) & $69.0 \pm 8.9$ & $67.5 \pm 8.2$ & $66.9 \pm 7.9$ & $67.8 \pm 10.1$ \\
\hline
\end{tabular}

Note: Values are presented as arithmetic mean \pm SD. 

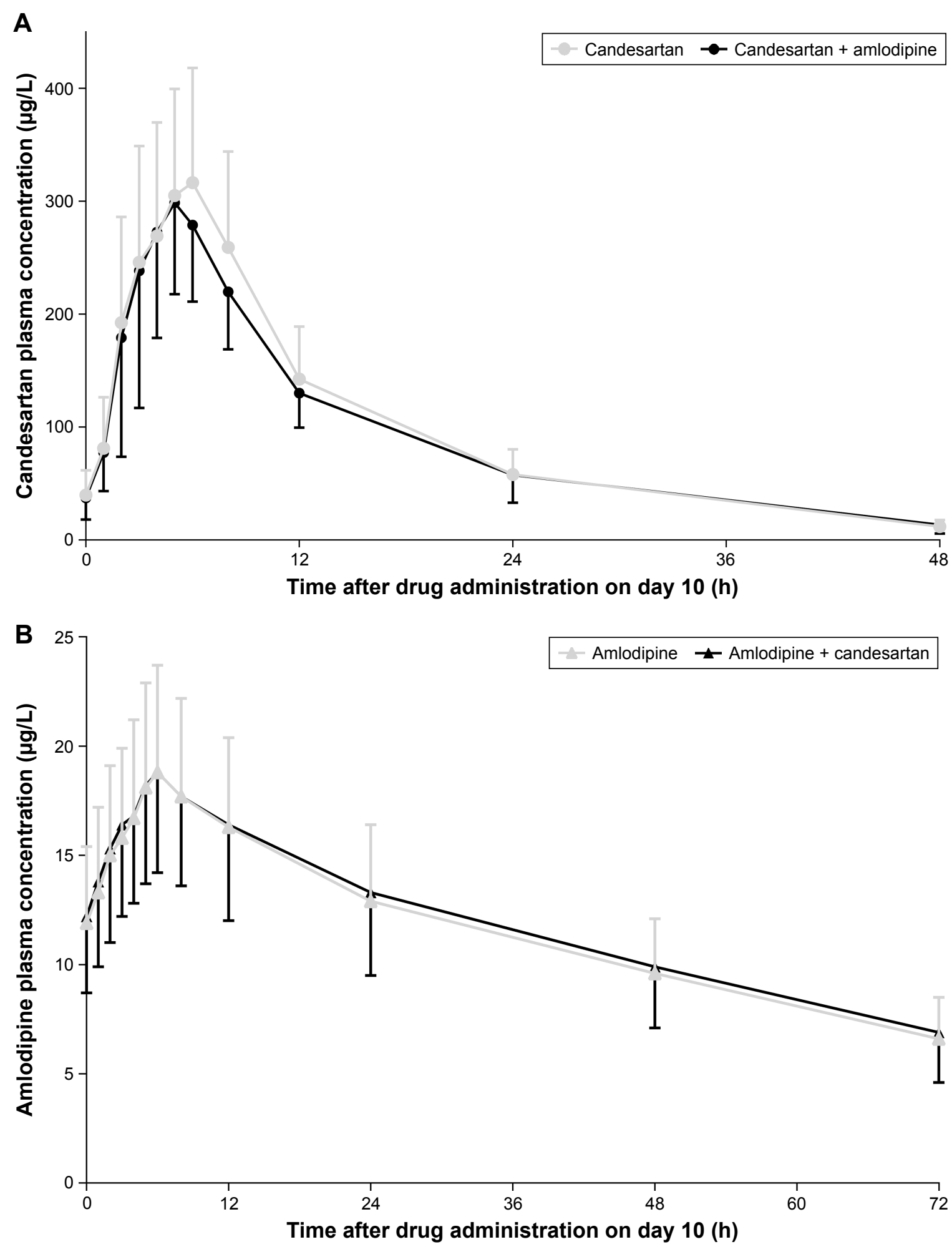

Figure I Mean (standard deviation) plasma concentration-time profiles of (A) candesartan and (B) amlodipine following multiple doses of the two drugs in the absence and presence of each other in healthy subjects.

\section{Blood pressure and pulse rate}

Candesartan, alone and in combination with amlodipine, showed similar profiles for the maximum change from baseline, although DBP was more decreased after combination with amlodipine than candesartan alone (Table 4). The maximum change in SBP and DBP on Day 10 were -19.5, -15.7 for amlodipine alone and $-26.4,-21.3$ for co-administration, respectively, and this difference reached statistical significance. 
Table 3 Pharmacokinetic parameters following multiple doses of candesartan $32 \mathrm{mg}$ and amlodipine $10 \mathrm{mg}$ in the absence and presence of each other in healthy subjects

\begin{tabular}{|c|c|c|c|c|c|}
\hline \multirow[t]{2}{*}{ Variable } & \multicolumn{2}{|c|}{ Geometric LSM (\% CV) } & \multirow[t]{2}{*}{ GMR } & \multicolumn{2}{|l|}{$90 \% \mathrm{Cl}$} \\
\hline & Combination & Alone & & Lower & Upper \\
\hline \multicolumn{6}{|l|}{ Candesartan } \\
\hline $\mathrm{AUC}_{\tau}(\mathrm{h} \cdot \mu \mathrm{g} / \mathrm{L})$ & $3,379.8(23.8)$ & $3,605.2(28.0)$ & 0.9375 & 0.8592 & 1.0229 \\
\hline $\mathrm{C}_{\max }(\mu \mathrm{g} / \mathrm{L})$ & $303.7(29.5)$ & $330.7(27.8)$ & 0.9186 & 0.8126 & 1.0384 \\
\hline $\mathrm{t}_{1 / 2}(\mathrm{~h})$ & I0.I (28.3) & $9.3(29.5)$ & & & \\
\hline$C_{\text {trough }}(\mu \mathrm{g} / \mathrm{L})$ & $33.5(5 \mid .5)$ & $34.7(55.0)$ & & & \\
\hline $\mathrm{t}_{\max }(\mathrm{h})^{\mathrm{a}}$ & $5.0(3.0-8.0)$ & $5.5(3.0-6.0)$ & & & \\
\hline \multicolumn{6}{|l|}{ Amlodipine } \\
\hline $\mathrm{AUC}_{\tau}(\mathrm{h} \cdot \mu \mathrm{g} / \mathrm{L})$ & $366.4(25.8)$ & $361.2(25.4)$ & 1.0146 & 0.9747 & 1.0562 \\
\hline $\mathrm{C}_{\max }(\mu g / L)$ & $18.6(24.2)$ & I $8.4(25.7)$ & 1.0128 & 0.9744 & 1.0528 \\
\hline $\mathrm{t}_{\mathrm{I} / 2}(\mathrm{~h})$ & $48.0(16.1)$ & $46.3(16.6)$ & & & \\
\hline$C_{\text {trough }}(\mu g / L)$ & II.7 (29.2) & II.3 (29.7) & & & \\
\hline $\mathrm{t}_{\max }(\mathrm{h})^{\mathrm{a}}$ & $6.0(5.0-8.0)$ & $6.0(2.0-12.0)$ & & & \\
\hline
\end{tabular}

Note: ${ }^{\vee}$ Values are presented as median (range).

Abbreviations: LSM, least squares mean; CV, coefficient of variation; GMR, geometric mean ratio; AUC, area under the curve.

Trends over time in vital signs on Day 10 are shown in Figure 2. As with the maximum change from baseline, there were significant differences in SBP and DBP between amlodipine alone and in combination with candesartan. For PR, however, any differences were not shown between interventions in both parts.

\section{Safety}

No serious TEAE was reported throughout the study, and all TEAEs were mild to moderate in severity and were recovered without sequelae. None of subjects discontinued the study due to TEAEs. Although more subjects experienced low DBP when administered candesartan in combination with amlodipine, there was no apparent difference in TEAE profiles between interventions in each part (Table 5).

\section{Discussion}

For the treatment of hypertensive patients, a rational combination of two antihypertensive drugs with different modes of action may be complicated by their drug-drug interactions. This study was performed to determine the potential for a drug interaction between candesartan and amlodipine in healthy subjects.

The present study demonstrated that amlodipine did not influence the rate and extent of candesartan absorption at steady state. In addition, the pharmacokinetics of amlodipine was not affected by multiple oral administrations of candesartan. Several studies have investigated pharmacokinetic interactions between ARBs and amlodipine. Multiple co-administrations of olmesartan $20 \mathrm{mg}$ and amlodipine $5 \mathrm{mg},{ }^{14}$ valsartan $320 \mathrm{mg}$ and amlodipine $10 \mathrm{mg},{ }^{15}$ and fimasartan $120 \mathrm{mg}$ and amlodipine $10 \mathrm{mg}^{16}$ did not show any clinical relevant change in the systemic exposure of both ARBs and amlodipine. Similar results were observed when S-amlodipine, an enantiomer of amlodipine, was co-administered with telmisartan. ${ }^{17}$ It should be noted that candesartan showed the relatively smallest degree of alteration in the pharmacokinetics of amlodipine among ARBs.

Table 4 The maximum change from baseline (CFB) in vital signs on Day 10 after co-administration of candesartan 32 mg and amlodipine $10 \mathrm{mg}$ and after administration of each drug alone in healthy subjects

\begin{tabular}{|c|c|c|c|c|}
\hline Variable & Combination & Alone & Difference $(95 \% \mathrm{Cl})$ & $p$-value \\
\hline \multicolumn{5}{|l|}{ Part I (candesartan) } \\
\hline Maximum CFB in SBP $(\mathrm{mmHg})$ & -26.2 & -25.8 & $-0.5(-3.6 \sim 2.7)$ & 0.7642 \\
\hline Maximum CFB in DBP $(\mathrm{mmHg})$ & -23.6 & -22.0 & $-1.5(-2.8 \sim-0.3)$ & 0.0176 \\
\hline Maximum CFB in PR (beats/min) & 6.4 & 6.2 & $0.2(-3.2 \sim 3.5)$ & 0.9232 \\
\hline \multicolumn{5}{|l|}{ Part 2 (amlodipine) } \\
\hline Maximum CFB in SBP $(\mathrm{mmHg})$ & -26.4 & -19.5 & $-6.9(-11.4 \sim-2.4)$ & 0.0053 \\
\hline Maximum CFB in DBP $(\mathrm{mmHg})$ & -21.3 & -15.7 & $-5.6(-8.7 \sim-2.6)$ & 0.0012 \\
\hline Maximum CFB in PR (beats/min) & 2.0 & 1.7 & $0.3(-4.2 \sim 4.8)$ & 0.8964 \\
\hline
\end{tabular}

Note: Values are least squares means.

Abbreviations: SBP, systolic blood pressure; DBP, diastolic blood pressure; PR, pulse rate. 

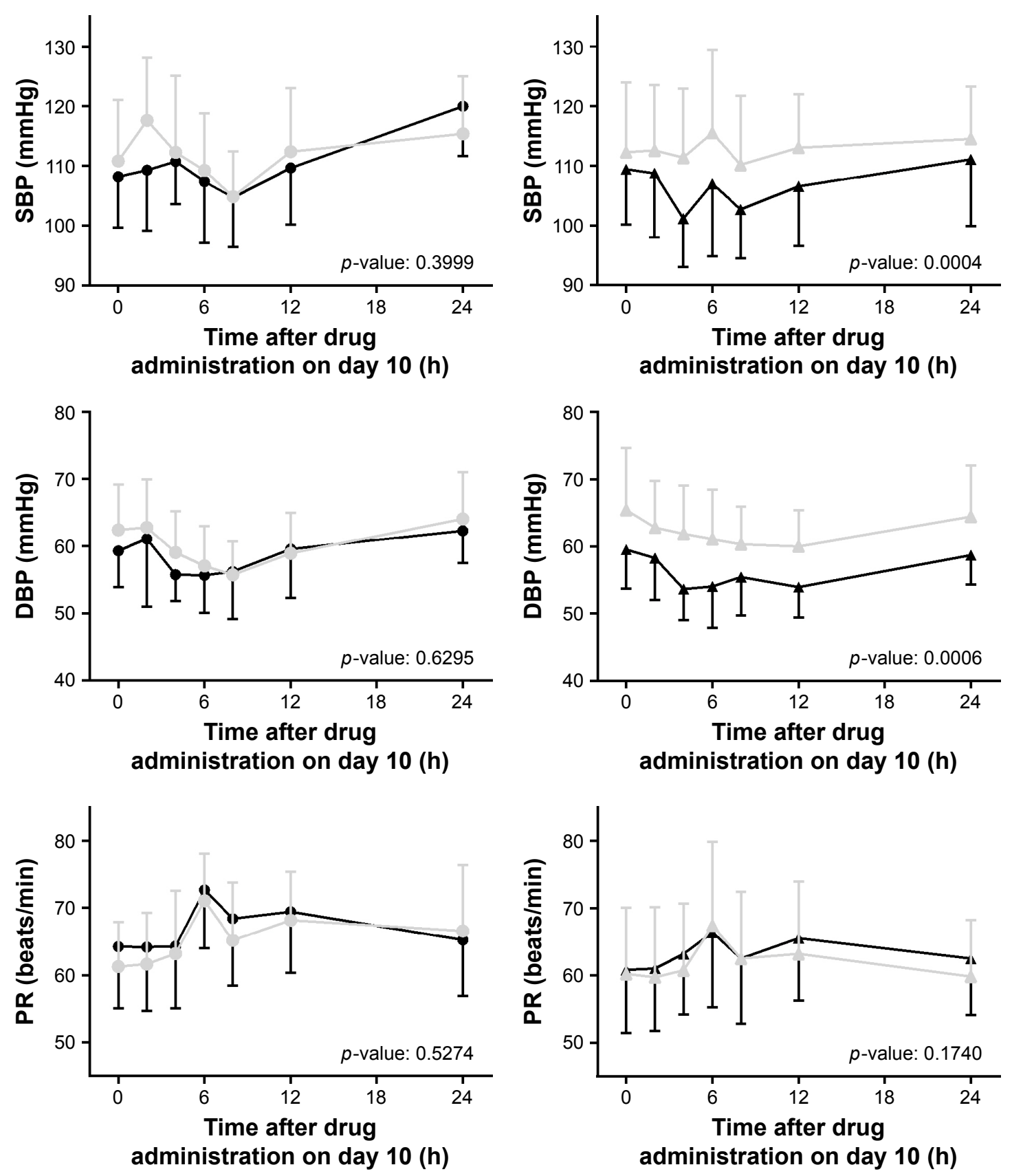

Candesartan $\rightarrow$ Candesartan + amlodipine

Amlodipine $\rightarrow$ Amlodipine + candesartan

Figure 2 Trends over time in vital signs after co-administration of candesartan $32 \mathrm{mg}$ and amlodipine $10 \mathrm{mg}$ and after administration of each drug alone in healthy subjects (left panel: part I, right panel: part 2).

Abbreviations: DBP, diastolic blood pressure; PR, pulse rate; SBP, systolic blood pressure.

The lack of pharmacokinetic interactions between candesartan and amlodipine can be attributed partly to their different disposition pathways. Candesartan is eliminated by renal and biliary excretion, ${ }^{11}$ while CYP enzymes, mainly CYP3A4, are involved in amlodipine metabolism. ${ }^{10}$ There are few drugs that affected the systemic exposure of amlodipine, except CYP3A4 inhibitors..$^{10}$ Candesartan has no effects on CYP enzymes at therapeutic concentrations, ${ }^{11}$ meaning candesartan is not considered as a CYP3A4 inhibitor. In addition, $\mathrm{P}$-glycoprotein (P-gp) is well known to play a significant role in drug absorption from the gastrointestinal lumen, indicating the modulation of P-gp can mediate drug-drug interactions. ${ }^{18}$ Candesartan is reported as a P-gp substrate,,${ }^{19}$ but amlodipine might be devoid of P-gp inhibiting 
Table 5 Treatment-emergent adverse event (TEAE) profiles after co-administration of candesartan and amlodipine and after administration of each drug alone in healthy subjects

\begin{tabular}{lll}
\hline Symptom and sign & $\begin{array}{l}\text { Combination } \\
(\mathbf{n = 2 0 )}\end{array}$ & $\begin{array}{l}\text { Alone } \\
(\mathbf{n}=\mathbf{2 0})\end{array}$ \\
\hline Part I (candesartan) & & \\
$\quad$ Blood pressure diastolic decreased & $3(3)$ & $2(2)$ \\
Dizziness postural & $\mathrm{I}(\mathrm{I})$ & $2(2)$ \\
Headache & $2(2)$ & - \\
$\quad$ Somnolence & $2(2)$ & - \\
Part 2 (amlodipine) & & \\
Palpitations & $\mathrm{I}(\mathrm{I})$ & $\mathrm{I}(\mathrm{I})$ \\
Blood pressure diastolic decreased & $6(6)$ & - \\
Headache & $\mathrm{I}(\mathrm{I})$ & $4(4)$ \\
Rhinorrhoea & - & $2(2)$ \\
\hline
\end{tabular}

Note: TEAEs that were reported at least twice are presented as number of subjects (number of events).

properties. ${ }^{20}$ Therefore, significant pharmacokinetic alterations both in amlodipine by candesartan and in candesartan by amlodipine are unlikely.

Although this study was conducted in normotensive subjects, BP lowering effects were observed in all intervention groups. Furthermore, co-administration of candesartan and amlodipine reduced BP more than amlodipine alone, but similar to candesartan alone. In patients with essential hypertension, however, it was found that the combination therapy of candesartan and amlodipine for 8-weeks reduced a mean sitting DBP more than candesartan or amlodipine alone. ${ }^{5}$ It should be noted that the administered dose in the present study was $32 \mathrm{mg}$ candesartan, not $16 \mathrm{mg}$. Considering the short period of 10 days in normotensive subjects, the interaction effects on lowering BP need to be interpreted with caution.

\section{Conclusion}

To our knowledge, this study is the first to investigate the pharmacokinetic interactions between candesartan and amlodipine. Co-administration of candesartan and amlodipine did not change the systemic exposure of each drug alone in healthy subjects. The administration of candesartan $32 \mathrm{mg}$ alone, amlodipine $10 \mathrm{mg}$ alone, and co-administration of candesartan and amlodipine were well tolerated during the study.

\section{Acknowledgments}

This study was sponsored by CJ Health Care., Ltd, Seoul, Republic of Korea. The sponsor was not involved in the study design or in the analysis and interpretation of data. The sponsor monitored this study during the whole clinical trial period.

\section{Author contributions}

All authors contributed toward data analysis, drafting and critically revising the paper, gave final approval of the version to be published, and agree to be accountable for all aspects of the work.

\section{Disclosure}

The authors report no conflicts of interest in this work.

\section{References}

1. James PA, Oparil S, Carter BL, et al. 2014 evidence-based guideline for the management of high blood pressure in adults: report from the panel members appointed to the Eighth Joint National Committee (JNC 8). JAMA. 2014;311(5):507-520.

2. Chobanian AV, Bakris GL, Black HR, et al. The Seventh Report of the Joint National Committee on Prevention, Detection, Evaluation, and Treatment of High Blood Pressure: the JNC 7 report. JAMA. 2003; 289(19):2560-2572.

3. Yamaguchi J, Hagiwara N, Ogawa H, et al. Effect of amlodipine + candesartan on cardiovascular events in hypertensive patients with coronary artery disease (from The Heart Institute of Japan Candesartan Randomized Trial for Evaluation in Coronary Artery Disease [HIJCREATE] Study). Am J Cardiol. 2010;106(6):819-824.

4. Rakugi H, Ogihara T, Miyata Y, Sasai K, Totsuka N. Evaluation of the efficacy and tolerability of combination therapy with candesartan cilexetil and amlodipine besilate compared with candesartan cilexetil monotherapy and amlodipine besilate monotherapy in Japanese patients with mild-to-moderate essential hypertension: a multicenter, 12-week, randomized, double-blind, placebo-controlled, parallel-group study. Clin Ther. 2012;34(4):838-848

5. Sohn IS, Kim CJ, Ahn T, et al. Efficacy and tolerability of combination therapy versus monotherapy with candesartan and/or amlodipine for dose finding in essential hypertension: a phase II multicenter, randomized, double-blind clinical trial. Clin Ther. 2017;39(8):1628-1638.

6. Kloner RA, Weinberger M, Pool JL, et al. Comparative effects of candesartan cilexetil and amlodipine in patients with mild systemic hypertension. Comparison of candesartan and amlodipine for safety, tolerability and efficacy (CASTLE) study investigators. Am J Cardiol. 2001;87(6):727-731.

7. Yasuno S, Fujimoto A, Nakagawa Y, Kuwahara K, Ueshima K. Fixeddose combination therapy of candesartan cilexetil and amlodipine besilate for the treatment of hypertension in Japan. Expert Rev Cardiovasc Ther. 2012;10(5):577-583.

8. Lee HS. New antihypertensive combos ready for market entry: Korea Biomedical Review; 2018. Available from: http://www.koreabiomed. com/news/articleView.html?idxno=2311. Accessed July 24, 2018.

9. Lin JH, Lu AY, Ay L. Inhibition and induction of cytochrome P450 and the clinical implications. Clin Pharmacokinet. 1998;35(5):361-390.

10. Norvasc ${ }^{\circledR}$ prescribing information. Available from: www.accessdata. fda.gov/drugsatfda_docs/label/2013/019787s054lbl.pdf. Accessed July 24, 2018.

11. Atacand ${ }^{\circledR}$ prescribing information. Available from: www.accessdata.fda. gov/drugsatfda_docs/label/2015/020838s036lbl.pdf. Accessed July 24, 2018.

12. Food U.S and U.S Administration. Clinical drug interaction studies study design, data analysis, and clinical implications guidance for industry; 2017. Available from: https://www.fda.gov/downloads/drugs/ guidances/ucm292362.pdf. Accessed July 24, 2018.

13. European Medicines Agency. Guideline on the investigation of drug interactions; 2012. Available from: http://www.ema.europa.eu/docs/ en_GB/document_library/Scientific_guideline/2012/07/WC500129606. pdf. Accessed July 24, 2018. 
14. Bolbrinker J, Huber M, Scholze J, Kreutz R. Pharmacokinetics and safety of olmesartan medoxomil in combination with either amlodipine or atenolol compared to respective monotherapies in healthy subjects. Fundam Clin Pharmacol. 2009;23(6):767-774.

15. Bhad P, Ayalasomayajula S, Karan R, et al. Evaluation of pharmacokinetic interactions between amlodipine, valsartan, and hydrochlorothiazide in patients with hypertension. J Clin Pharmacol. 2011;51(6):933-942.

16. Yi S, Kim TE, Yoon SH, et al. Pharmacokinetic interaction of fimasartan, a new angiotensin II receptor antagonist, with amlodipine in healthy volunteers. J Cardiovasc Pharmacol. 2011;57(6):682-689.

17. Noh YH, Lim HS, Kim MJ, et al. Pharmacokinetic interaction of telmisartan with s-amlodipine: an open-label, two-period crossover study in healthy Korean male volunteers. Clin Ther. 2012;34(7):1625-1635.

18. Lin JH. Drug-drug interaction mediated by inhibition and induction of P-glycoprotein. Adv Drug Deliv Rev. 2003;55(1):53-81.
19. Zhou L, Chen X, Gu Y, Liang J. Transport characteristics of candesartan in human intestinal Caco-2 cell line. Biopharm Drug Dispos. 2009; 30(5):259-264.

20. Zhou SF, Xue CC, Yu XQ, Li C, Wang G. Clinically important drug interactions potentially involving mechanism-based inhibition of cytochrome P450 3A4 and the role of therapeutic drug monitoring. Ther Drug Monit. 2007;29(6):687-710.

21. Tjandrawinata RR, Setiawati E, Yunaidi DA, Simanjuntak R, Santoso ID, Susanto LW. Bioequivalence study of two formulations of candesartan cilexetil tablet in healthy subjects under fasting conditions. Drug Des Devel Ther. 2013;20(7):841-847.

22. Liu Y, Jia J, Liu G, et al. Pharmacokinetics and bioequivalence evaluation of two formulations of 10-mg amlodipine besylate: an open-label, single-dose, randomized, two-way crossover study in healthy Chinese male volunteers. Clin Ther. 2009;31(4):777-783.

\section{Publish your work in this journal}

Drug Design, Development and Therapy is an international, peerreviewed open-access journal that spans the spectrum of drug design and development through to clinical applications. Clinical outcomes, patient safety, and programs for the development and effective, safe, and sustained use of medicines are the features of the journal, which has also been accepted for indexing on PubMed Central. The manuscript management system is completely online and includes a very quick and fair peer-review system, which is all easy to use. Visit http://www.dovepress.com/testimonials.php to read real quotes from published authors.

Submit your manuscript here: http://www.dovepress.com/drug-design-development-and-therapy-journal 